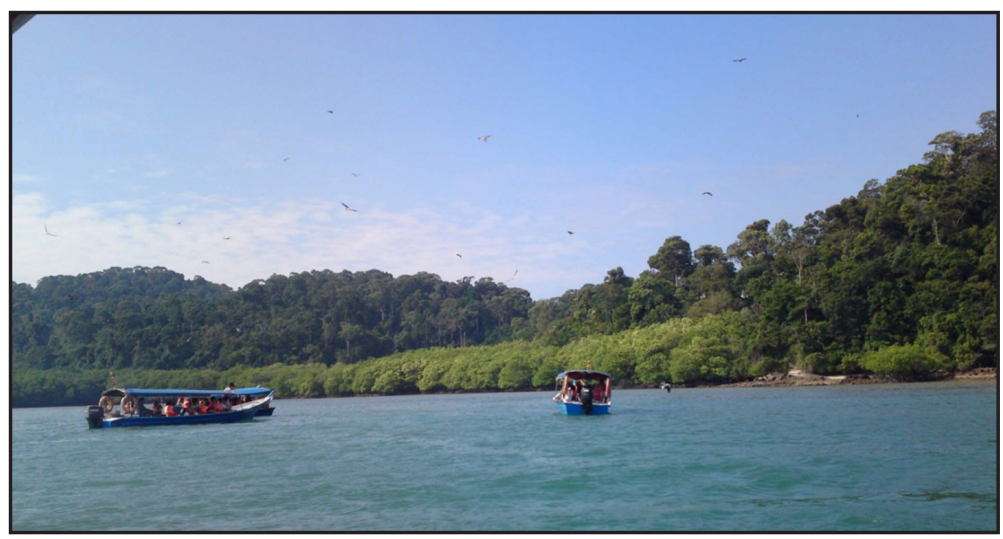

Рис. 2. Место кормиения белобрюхих орланов (6¹3'19.96” N, 9944’04.03” E) на о. Пулау Бесар Санга, о-ва Аангкави. Фото А. Хамегизацэ.

Fig. 2. Feeding location of White-Bellied Sea Eagles (6¹3'19.96” N, 9944'04.03” E), Pulau Sanga Besar, Langkawi Island. Photo by A. Khaleghizadeh.

положено место кормления, гАе туристы кидают куски курицы, чтобы привлечь белобрюхих орланов, а также браминского коршуна (Haliastur indus) (рис. 2).

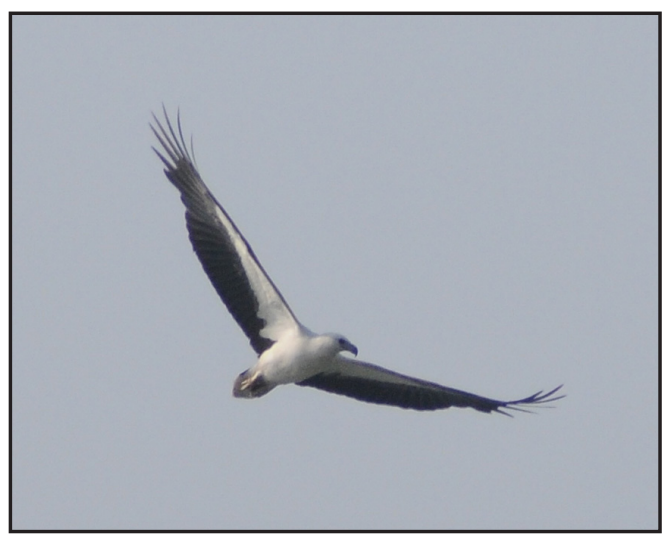

Белобрюхий орлан. Фото О. Белялова. White-Bellied Sea Eagle. Photo by O. Belyalov.

Khaleghizadeh A. \& Anuar S. Factors affecting nest-site selection of the White-Bellied Sea Eagle Haliaeetus leucogaster (Gmelin, 1788) in coastal rainforests, Peninsular Malaysia. - Tropical Ecology. (in press).

\title{
The New Record of Breeding Pairs of the Booted Eagle in the National Park "Nizhnyaya Kama" in 2015, Republic of Tatarstan, Russia
}

\section{НОВАЯ НАХОДКА ГНЕЗДЯЩЕЙСЯ ПАРЫ ОРЛОВ-КАРЛИКОВ В НАЦИОНАЛЬНОМ ПАРКЕ «НИЖНЯЯ КАМА» В 2015 ГОДУ, РЕСПУБЛИКА ТАТАРСТАН, РОССИЯ}

\author{
Bekmansurov R.H. (Elabuga Institute, Kazan Federal University; NP "Nizhnyaya Kama", \\ Elabuga, Republic of Tatarstan, Russia)
}

Бекмансуров Р.X. (Елабужский институт Казанского федерального университета; Национальный парк «Нижняя Кама», Елабуга, Республика Татарстан, Россия)

\section{Контакт:}

Ринур Бекмансуров, Елабужский институт Казанского фелераиьного университета; Национаиьный парк "Нижняя Кама", 423607, Россия, Республика Татарстан, Елабуга,

ул. Казанская, 89 , тел.: +785557 75455 rinur@yandex.ru

DOI: $10.19074 / 1814-8654-2015-30-115-117$

Opёл-карлик (Hieraaetus pennatus) является слабо изученным видом на территории Республики Татарстан (РТ), как впрочем, и на большей части его гнездового ареала. Находки гнёзд орлов-карликов привносят новые представления о распространении вида. С 1960-х годов на востоке Европы наметилась тенденция к расширению ареала в северо-восточном направлении, в том

Орёл-карлик (Hieraaetus pennatus). Фото Р. Бекмансурова.

Booted Eagle (Hieraaetus pennatus). Photo by R. Bekmansurov.
A new nest of the Booted Eagle (Hieraaetus pennatus) was found in the north-east of the Republic of Tatarstan on the May 7, 2015 during the examination of Nizh-

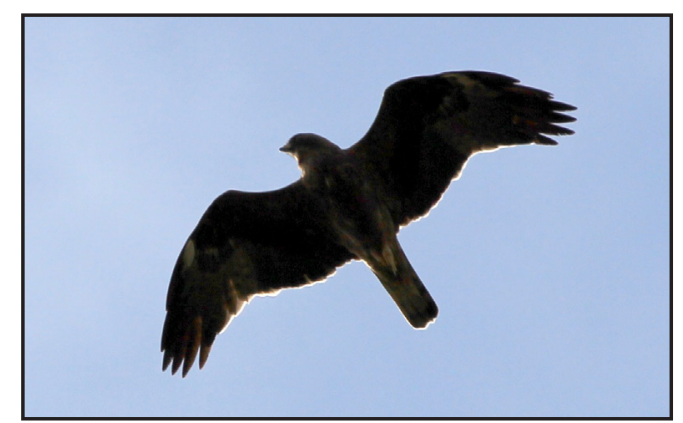




\section{Contact:}

Rinur Bekmansurov,

Elabuga Institute, Kazan Federal University;

National Park

"Nizhnyaya Kama"

Kazaknskaya str., 89 Elabuga

Republic of Tatarstan

Russia, 423600

tel.: +7 8555775455

rinur@yandex.ru
Pис. 1. Гнездо орлакарлика (Hieraaetus pennatus) в кроне сосны.

Фото Р. Бекмансурова.

Fig. 1. The nest of the Booted Eagle (Hieraaetus pennatus) in the pine tree. Photo by R. Bekmansurov. числе распространение вида происходило и на территории Татарстана. Так, здесь $\Delta$ о конца XX века орёл-карлик считался очень редким залётным видом. Но уже в конце 1990-х годов отмечены пары с брачным и гнездовым поведением в Верхнеуслонском, Камско-Устьинском и Ааишевском районах (Аськеев, Аськеев, 1999; 2006). В начале XXI века выявлены плотная гнезАовая группировка не менее 10 пар в Тетюшском районе РТ (Корепов, 2006) вдоль р. Волга (Шучьи горы), 3 гнездовых участка в Бавлинском и Бугульминском районах (Карякин, 2006; 2007) и 2 гнездовых участка на правобережье р. Кама в Мамахышском и Елабужском районах (Николенко, Бекмансуров, 2006). За последние 10 лет Аополнительно отмечено гнездование в Верхнеуслонском (1 пара), Ааишевском (1 пара), Пестречинском (1 пара), РыбноСлободском (1 пара), Тукаевском (1 пара), Агрызском (1 пара) районах (О.В. Аськеев, мичное сообшение; А.С. Аюпов, кичное сообщение; ханные автора). Разрозненные находки гнёзд этого вида в Татарстане, показывают, что орёл-карлик освоил значительную территорию республики. Вид занесён в Красную книгу РТ. Численность в Татарстане ешё в 2007 г. оценена не менее 77 гнездяшихся пар (Карякин, 2007), при этом лишь на участке Шучьи Горы в Тетюшском районе численность оценивалась в 10-20 пар (Корепов, 2006). Скорее всего, современная численность вида в Татарстане приближается к 100 парам или даже выше.

В Татарстане орёл-карлик тяготеет преимушественно к Аостаточно крупным по плошали лесным массивам вАоль крупных рек. Гнездится как в чистых широколиственных лесах, так и в смешанных лесах на месте боров и в борах. Не искиючено появление гнёзд в небольших островных

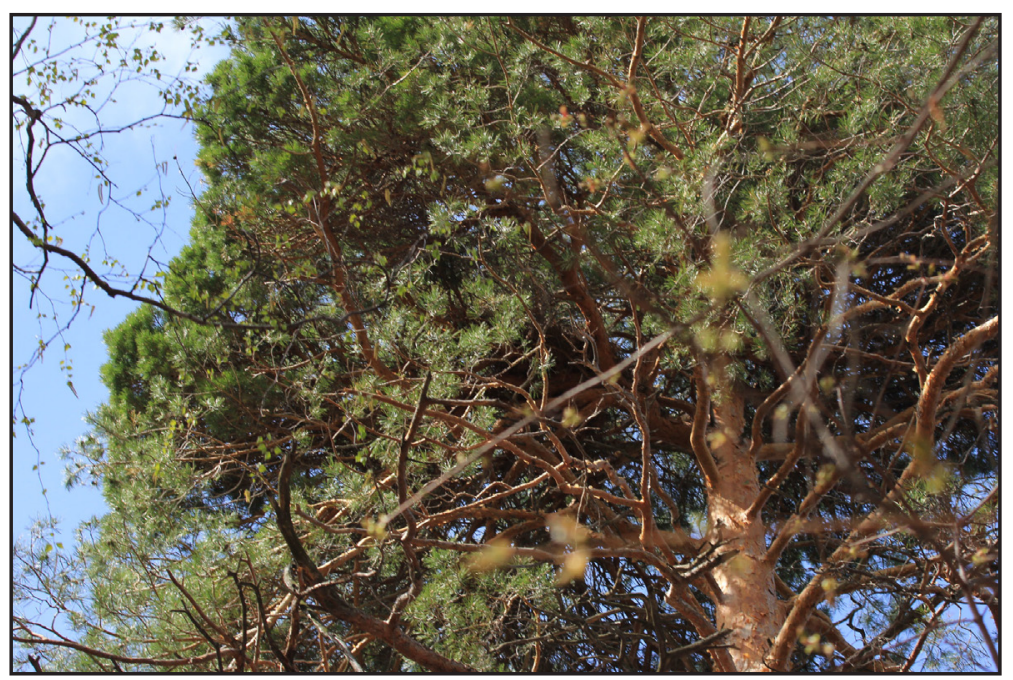

nekamsk reservoir coast site in Borovetsky forest of the Nizhnyaya Kama National Park. This woodland has the area of $93.44 \mathrm{~km}^{2}$ and it borders the left coast of the reservoir. The nest is situated on the upper part of a pine on an offshoot at about $25 \mathrm{~m}$ above the ground and $5 \mathrm{~m}$ from the top of the pine. The nest is hidden in crown (fig. 1). The location of the pine is on the ledge of the coast slope. Under the nest runs a track used for hiking, skiing and bicycling. Recreation centers and summer camps are situated nearby (0.18 and $0.35 \mathrm{~km}$ respectively). Male and female are of different morphs: light and dark (fig. 2). The Booted Eagle's nest in given forest area was discovered for the first time. The closest nesting ground was known in $10.4 \mathrm{~km}$ on the left bank of Kama (Niznekamsk reservoir) in Bolshoy Bor forest with similar location.

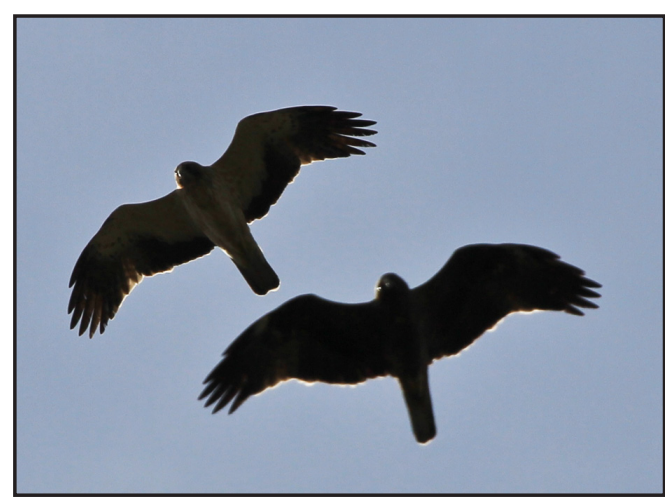

Pис. 2. Пара орлов-карликов: самец светлой морфы, самка - тёмной морфы. Фото Р. Бекмансурова.

Fig. 2. The breeding pair of the Booted Eagle: male - light morph, female - dark morph. Photo by R. Bekmansurov.

лесах и колках. Гнёзда строит на расстоянии не более 300-500 м от опушки на меревьях, в основном на соснах (Pinus sylvestris), Аубах (Quercus sp.), липах (Tilia cordata), тополях (Populus nigra), берёзах (Betula sp.), устраивая их в развилке ствола или в основании боковых ветвей. Большинство известных гнёзА ориентировано к реке с расположением на уступах террас и склонов. Возможно гнездование в поймах рек, как это известно, в Самарской области (Карякин, Николенко, 2008; Карякин, Паженков, 2008) и Башкирии (Карякин, 2006).

Новое гнездо обнаружено на северо-востоке Республики Татарстан 7 мая 2015 г. во время обследования участка побережья 


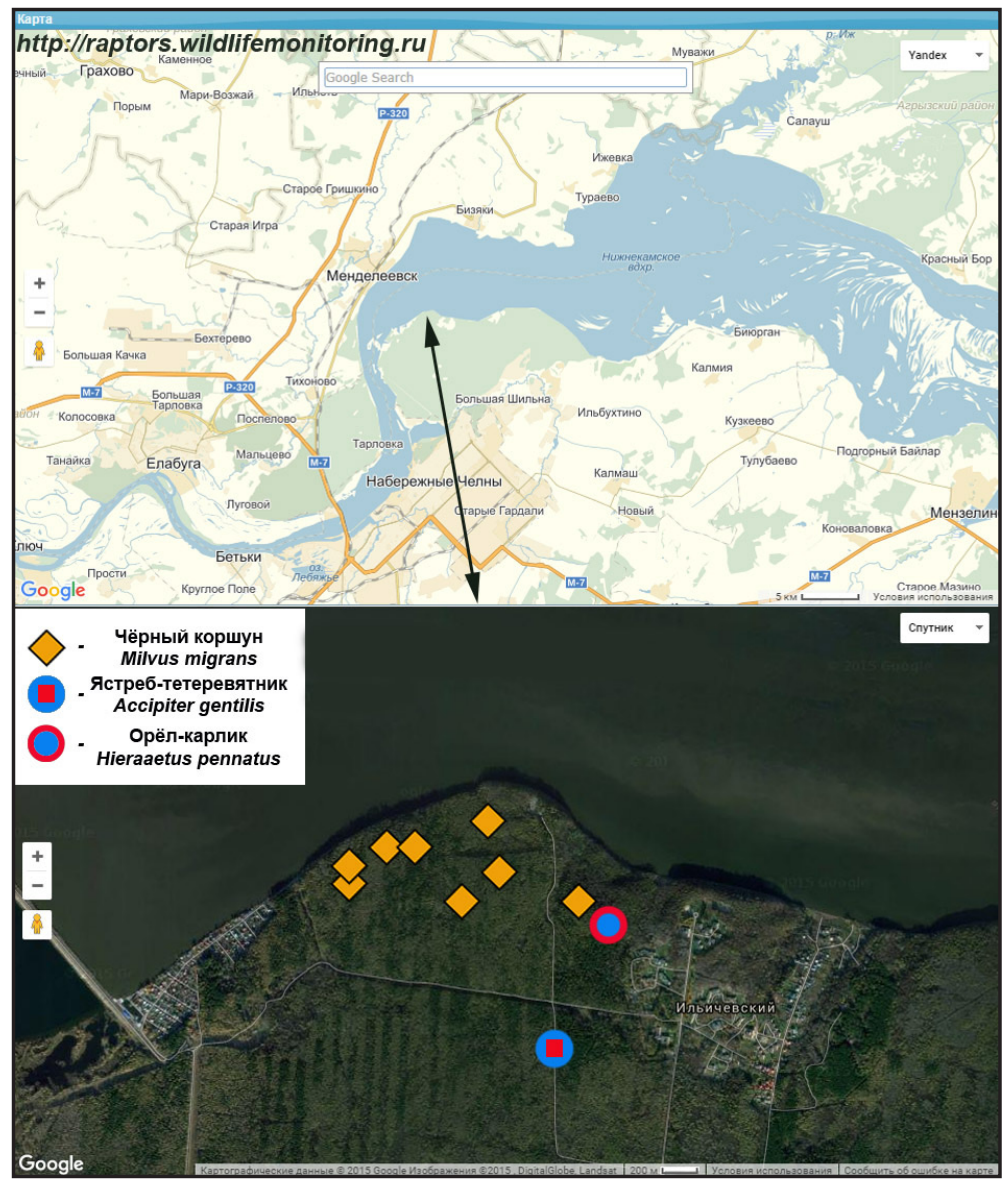

Нижнекамского водохранилища в Боровецком лесу национального парка "Нижняя Кама". Аанный лесной массив плошаАью 93,44 км² примыкает к левому берегу водохранилища. Обследован участок плошадью около 1,3 км². ГнезАо расположено в верхней части сосны на боковой ветви на высоте около 25 м и 5 м от вершины. ГнезАо скрыто в кроне (рис. 1). Месторасположение сосны - пологий береговой скион. Под гнезАом проходит Аорожка, используемая мия пеших, велосипедных и лыжных прогулок. Поблизости расположены базы отдыха и детские оздоровительные лагеря (Аистанции 0,18 и 0,35 км соответственно). Расстояние $\Delta$ о берега 0,34 км, $\Delta$ о асфальтированной Аороги в лесу - 0,27 км. Птицы выдаяи себя характерным свистом. Самка покинула гнездо и вместе с самцом летаии нац гнездом. Самец и самка разной морсы: светлой и тёмной (рис. 2).

На обследованном участке дополнительно обнаружена колония чёрных коршунов (Milvus migrans) из 7 гнездовых участков С гнёздами на соснах и берёзах. Из них 6 определены как жилые и в них шло насиживание. Аистанция Ао ближайшего и Аацьнего жилых гнёзд коршунов - 0,2 и 1,3 км. Расположение гнезда орлов-кармиков относительно колонии коршунов - с
Рис. 3. Обслелованный участок Боровецкого леса с гнёздами орла-карлика (Hieraaetus pennatus), чёрных коршунов (Milvus migrans) и ястреба-тетеревятника (Accipiter gentilis).

Fig. 3. The Borovetskiy forest where were found nests of the Booted Eagle (Hieraaetus pennatus), Black Kite (Milvus migrans) and Goshawk (Accipiter gentilis).

краю. Кроме того, в 0,69 км расположено старое гнездо тетеревятника (Accipiter gentilis) (рис. 3).

Гнездо орла-карлика в данном лесном массиве обнаружено впервые. Ближайший гнездовой участок был известен в 10,4 км на правом берегу Камы (Нижнекамское водохранилише) в лесном массиве Большой Бор со сходным месторасположением. Но этот участок остался незанятым после гибели одного из партнёров.

\section{Аитература}

Аськеев И.В., Аськеев О.В. Орнитосрауна Республики Татарстан (конспект современного состояния). Казань, 1999. 123 с.

Аськеев И.В., Аськеев О.В. Орёл-карлик. Красная книга Республики Татарстан. Казань, 2006. С. 78-79.

Карякин И.В. Новые Аанные о гнездовании орла-карлика на Бугульминско-Белебеевской возвышенности. - Труды Государственного природного биоссерного заповедника "Керженский”. 2006. Т. 3. С. 102-103.

Карякин И.В. Орёл-карлик в Поволжье, на Ураяе и в Сибири, Россия. - Пернатые хищники и их охрана. 2007. № 9. С. 27-62 [Karyakin I.V. The Booted Eagle in the Volga Region, Ural and Siberia, Russia. - Raptors Conservation. 2007. 9: 27-62].

Карякин И.В., Николенко Э.Г. Хишные птицы Аолины р. Самара. - Пернатые хишники и их охрана. 2008. № 12. С. 59-68 [Karyakin I.V., Nikolenko E.G. Birds of Prey in the Samara River Valley, Russia. - Raptors Conservation. 2008. 12: 59-68].

Карякин И.В., Паженков А.С. Хишные птицы Самарской области. Книга-фотоаньбом. Самаpa, 2008. 66 c.

Корепов М.В. Новые Аанные о гнездовании орла-карлика и орлана-белохвоста в урочише «Шучьи горы", Россия. - Пернатые хишники и их охрана. 2006. № 7. С. 67-69 [Korepov M.V. New records of breeding the Booted Eagle and the White-Tailed Eagle in the natural boundary "Schuchy Gory", Russia. - Raptors Conservation. 2006. 7: 67-69].

Николенко Э.Г., Бекмансуров Р.Х. Новые находки орла-карлика на гнездовании в Татарстане. - Пернатые хишники и их охрана. 2006. № 6. C. 65-66 [Nikolenko E.G., Bekmansurov R.H. New records of breeding the Booted Eagle in the Republic of Tatarstan. - Raptors Conservation. 2006. 6: 65-66]. 